\title{
PREMI TUNGGAL ASURANSI JIWA EQUITY-LINKED : ANALISIS PENGARUH USIA TERTANGGUNG DAN WAKTU JATUH TEMPO
}

\author{
Yunita Wulan Sari, Gunardi \\ Program Studi Statistika, Juruan Matematika, FMIPA, UGM \\ Sekip Utara, Bulaksumur, Yogyakarta, \\ yunita-ws@ugm.ac.id.
}

\begin{abstract}
ABSTRAK
Asuransi jiwa unit-linked adalah produk asuransi jiwa yang bersifat hibrida karena memberikan dua manfaat sekaligus, yakni manfaat perlindungan santunan asuransi jiwa dan manfaat investasi dalam bentuk nilai tunai. Asuransi equity-linked merupakan salah satu jenis asuransi unit-linked yang menginvestasikan sebagian premi yang dibayarkan pada saham. Beberapa polis asuransi jiwa tersebut menyertakan opsi yang memberi hak pemegang polis untuk mengakhiri kontrak polis dan menerima sejumlah uang tunai. Pada penelitian ini, akan diteliti bagaimana menentukan besarnya premi tunggal asuransi jiwa dwiguna equity-linked dengan menggunakan pohon binomial harga saham Telekomunikasi Indonesia (TLKM.JK) kemudian dilakukan analisis pengaruh usia tertanggung dan waktu jatuh tempo kontrak polis terhadap harga premi tersebut. Dari penelitian ini diharapkan diperoleh harga premi yang wajar.
\end{abstract}

Kata Kunci : premi tunggal, asuransi jiwa dwiguna, equity-linked, surrender option.

\begin{abstract}
Unit-linked life insurance is a life insurance product that is hybrid because it provides two benefits at the same time, the benefits of protection and investment. Equity-linked is one type of unit-linked insurance that invests some of the premium paid on the stock. Some of this insurance include the option which entitles the policyholder to terminate the policy contract and receive some cash. In this research, it will be investigated how to determine the amount of single premium of unit-linked endowment life insurance using a stock price binomial tree of Telekomunikasi Indonesia Tbk. (TLKM.JK), then analyzed the influence of the age and policy maturity to the contract price of the premium. From this research, it is expected to be obtained reasonable premium price.
\end{abstract}

Keywords: single premium, endowment life insurance, equity-linked, surrender option.

\section{Pendahuluan}

Dalam rencana keuangan, investasi dan proteksi adalah dua hal yang harus dimiliki. Unit-linked merupakan produk perusahaan asuransi jiwa yang menggabungkan dua fungsi tersebut yang mulai diperkenalkan pada tahun 1970-an sampai 1980-an ketika tingkat suku bunga jangka panjang tinggi [1]. Jenis asuransi jiwa ini menawarkan banyak pilihan investasi, diantaranya saham, obligasi, pasar uang, serta campuran dari saham dan obligasi. Equity unit-linked atau equity-linked menginvestasikan minimal $80 \%$ premi pada saham. Oleh 
karena itu, beberapa polis asuransi jiwa dwiguna jenis ini menyertakan opsi jual tipe amerika yang memberi hak pemegang polis untuk mengakhiri kontrak polis dan menerima sejumlah uang tunai [2]. Selain itu pemegang polis akan mendapatkan manfaat atau imbal hasil pada saat jatuh tempo jika dia masih hidup atau pada saat dia meninggal dunia sebelum waktu jatuh tempo selama hak opsi tidak dilaksanakan. Anna Rita Bacinello (2008) menggunakan pendekatan Monte Carlo untuk menghitung valuasi harga premi asuransi jiwa dana saham yang memberikan hak opsi [3]. Harga premi asuransi dana saham juga dapat dihitung dengan model bivariat [4]. Langkah pertama yang digunakan dalam model ini adalah mentransformasi model pergerakan harga saham dan volatilitasnya dalam dua difusi, kemudian mentransformasi pergerakan tingkat suku bunga menggunakan auxiliary process orthogonal. Pada penelitian ini, akan dibahas bagaimana menentukan premi tunggal asuransi jiwa dwiguna equitylinked. Premi asuransi yang kita bayarkan sekali pada awal kontrak polis tersebut seharusnya juga mencerminkan bagaimana pergerakan harga saham kedepan. Pohon binomial adalah salah satu metode yang digunakan untuk memprediksi pergerakan harga saham tersebut.

Misalkan polis asuransi dwiguna equity-linked diterbitkan pada saat $\mathrm{t}=0$ dan jatuh tempo T. Diasumsikan waktu dalam satuan tahun dan $\mathrm{T}$ adalah bilangan bulat positif. Dinotasikan $\mathrm{x}$ adalah usia tertanggung pada saat kontrak ditan-datangani. Jika D adalah jumlah yang diinvestasikan, $S_{t}$ adalah harga saham pada $t>0$ dan $S_{0}>0$, maka unit saham yang diperoleh adalah $n=\frac{D}{S_{0}}$. Nilai akumulasi investasi pada saat $\mathrm{t}$ menjadi $F_{t}=n S_{t} . \quad$ Pada asuransi dwiguna, perusa-haan asuransi wajib membayar manfaat pada saat tertanggung meninggal dunia atau pada saat jatuh tempo, mana yang terjadi terlebih dahulu.

- $C_{t}^{M}=f_{t}^{M}\left(F_{t}\right) \quad$ manfaat yang dibayarkan pada saat tertanggung meninggal dunia sebelum waktu jatuh tempo.

- $C_{t}^{V}=f_{t}^{V}\left(F_{t}\right) \quad$ manfaat yang dibayarkan pada saat waktu jatuh tempo karena tertanggung masih hidup.

$C_{t}^{M}$ dan $C_{t}^{V}$ salah satunya harus fungsi konstanta atau fixed. Kewajiban ini akan melekat terus sampai jatuh tempo apabila tertanggung tidak menggunakan hak opsinya. Pada kasus opsi dilaksanakan pada saat $\mathrm{t}(0<\mathrm{t}<\mathrm{T})$, perusahaan asuransi 
wajib membayar sejumlah $\mathrm{R}_{\mathrm{t}} \leq \mathrm{C}_{\mathrm{t}}^{\mathrm{M}}$. Tentu saja keputusan tertanggung untuk melaksanakan hak opsinya sangat dipengaruhi oleh nilai investasi dan harga saham di pasar [5].

Pada penelitian ini, akan diteliti bagaimana menentukan besarnya premi tunggal asuransi jiwa dwiguna equitylinked dengan menggunakan pohon binomial harga saham Telekomunikasi Indonesia (TLKM.JK). Dari penelitian ini diharapkan diperoleh harga premi yang wajar.

\section{Metode Penelitian}

Prosedur penelitian yang dilakukan adalah membuat pohon binomial forward untuk harga saham kemudian dilanjutkan dengan membuat pohon binomial backward untuk premi asuransi. Pengaplikasian pada data riil dilakukan pada saham Telekomunikasi Indonesia (TLKM.JK) untuk mendapatkan harga premi tunggal asuransi jiwa equity-linked yang wajar pada usia tertanggung dan waktu jatuh tempo tertentu.

\section{Pohon Binomial Harga Saham}

Apabila polis asuransi jiwa berlaku mulai pada saat ditandatangani $(\mathrm{t}=0)$ sampai waktu jatuh tempo $\mathrm{T}$, maka interval waktu $[0, \mathrm{~T}]$ tersebut dapat dibagi dalam $\mathrm{N}$ waktu diskret, yakni $[(\mathrm{i}-1) \mathrm{h}$, ih], $\mathrm{i}=1,2,3, \ldots, \mathrm{N}$. Tiap jangka waktu diskret panjangnya adalah $h=\frac{T}{N}$. Harga saham pada pasar bebas pada kenyataannya akan selalu berubah naik atau turun seiring dengan perubahan waktu. Kemungkinan dua arah perubahan inilah yang digunakan sebagai dasar model binomial. Misalkan harga saham pada saat $\mathrm{t}=0$ adalah $\mathrm{S}_{0}$ dan pada saat $\mathrm{t}+1$ akan naik dengan peluang p menjadi $S_{t+1}^{u}$ atau akan turun dengan peluang 1-p menjadi $S_{t+1}^{d}$.

Diketahui model stokastik untuk harga saham

$$
d \ln \left(S_{t}\right)=\left(\mu_{s}-\frac{1}{2} \sigma_{s}^{2}\right) d t+\sigma_{s} d W_{t}
$$

$\mu_{s}$ dan $\sigma_{s}$ adalah parameter yang tidak diketahui dan independen terhadap waktu. Kedua parameter tersebut dapat diestimasi dengan data historis saham. $\mathrm{W}_{\mathrm{t}}$ adalah Brownian motion standar [6]. Berdasarkan model harga saham tersebut, tiap jangka waktu diskret yang panjangnya adalah $\mathrm{h}$ berlaku $\ln \left(S_{t+1}^{u}\right)=\ln \left(S_{t}\right)+\sigma_{s} \sqrt{h} \quad$ dan $\ln \left(S_{t+1}^{d}\right)=\ln \left(S_{t}\right)-\sigma_{s} \sqrt{h}$. Oleh karena itu, dapat didefinisikan harga saham pada saat $\mathrm{t}+1$ jika diketahui harga saham pada saat $\mathrm{t}$, yaitu

$$
S_{t+1}^{u}=S_{t} e^{\sigma_{s} \sqrt{h}}
$$

dan 


$$
S_{t+1}^{d}=\frac{S_{t}}{e^{\sigma_{s} \sqrt{h}}}
$$

Alur pembentukan pohon binomial harga saham ditunjukkan pada gambar berikut:

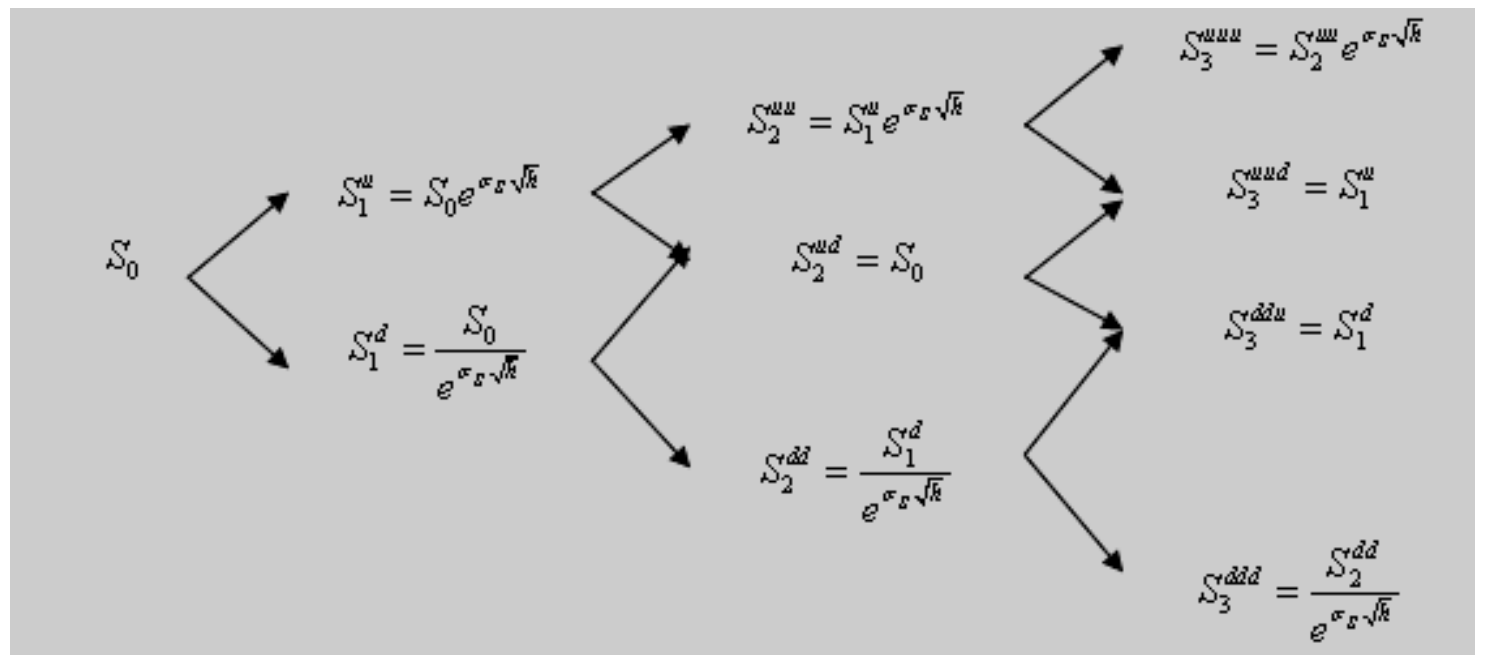

Gambar 1. Alur Pembentukan Pohon Binomial Harga Saham.Pohon Binomial Premi

\section{Tunggal Asuransi Jiwa Equity-Linked}

Pada penelitian ini digunakan asuransi jiwa dwiguna, dimana pemegang polis atau tertanggung akan menerima manfaat polis jika meninggal dunia pada saat $\mathrm{t}(0<\mathrm{t}<\mathrm{T})$ atau masih hidup pada saat T selama hak opsinya tidak dilaksanakan. Diketahui polis berlaku pada interval waktu $[0, \mathrm{~T}]$ dan dibagi dalam $\mathrm{N}$ waktu diskrit, sehingga ada beberapa ketentuan dalam peyusunan pohon binomialnya, yaitu :

- Pada kasus kematian terjadi antara $\mathrm{t}$ dan $\mathrm{t}+1$, manfaat polis $\mathrm{C}_{\mathrm{t}}^{\mathrm{M}}=\mathrm{M}$ bernilai konstan dan dibayarkan pada saat $\mathrm{t}+1$.

- Hak opsi dapat dilaksanakan di setiap awal sub interval $t>0$. jika hak opsi dilaksanakan, maka perusahaan asuransi wajib membayar sejumlah $\mathrm{R}$ yang bernilai konstan dan $\mathrm{R} \leq \mathrm{M}$.
- Jika pemegang polis masih hidup sampai awal periode $\mathrm{t}$ dan hak opsi belum pernah dilaksanakan sebelumnya, maka pemegang polis mempunyai 2 al-ternatif :

1. Melaksanakan hak opsinya dan berarti kontrak polis berakhir.

2. Melanjutkan kontrak dan jika pada interval $[t, t+1]$ meninggal dunia, maka kontrak polis berakhir pada $\mathrm{t}+1$.

Berdasarkan ketentuan diatas, nilai kontinu kontrak polis adalah

$$
W_{t}={ }_{h} q_{x+i h}\left(e^{-r h} M\right)+{ }_{h} p_{x+i h}\left(e^{-r h}\left(0.5 V_{t+1}^{u}+0.5 V_{t+1}^{d}\right)\right)
$$

Nilai kontrak pada saat $\mathrm{t}$ termasuk kompensasi jika hak opsi dilaksanakan adalah :

$$
V_{t}=\max \left(R, W_{t}\right)
$$

dimana ${ }_{h} q_{x+i h}$ adalah peluang tertanggung 
yang berusia $\mathrm{x}+\mathrm{ih}$ akan bertahan hidup sampai h tahun kemudian. ${ }_{h} p_{x+i h}$ adalah peluang tertanggung yang berusia $\mathrm{x}+\mathrm{ih}$ akan meninggal dalam jangka waktu $h$ tahun ke depan. $r$ adalah suku bunga acuan. $V_{t+1}^{u}$ adalah nilai $V_{t+1}$ pada posisi naik dan $V_{t+1}^{d}$ adalah nilai $V_{t+1}$ pada posisi turun.

\section{Aplikasi pada Data Saham TLKM.JK}

Berdasarkan pembahasan diatas, akan dihitung besarnya premi tunggal yang harus dibayarkan seseorang yang ingin mendapatkan manfaat asuransi jiwa sekali-gus berinvestasi pada saham TLKM.JK pada awal Oktober 2014. Data historis saham TLKM.JK pada Oktober 2004-Oktober 2014 digunakan untuk mengestimasi volatilitas pergerakan harga saham. Nilai ${ }_{h} q_{x+i h}$ didapatkan dari Tabel Mortalita Indonesia (TMI) III tahun 2011. Penghitungan premi dilakukan dengan software R.

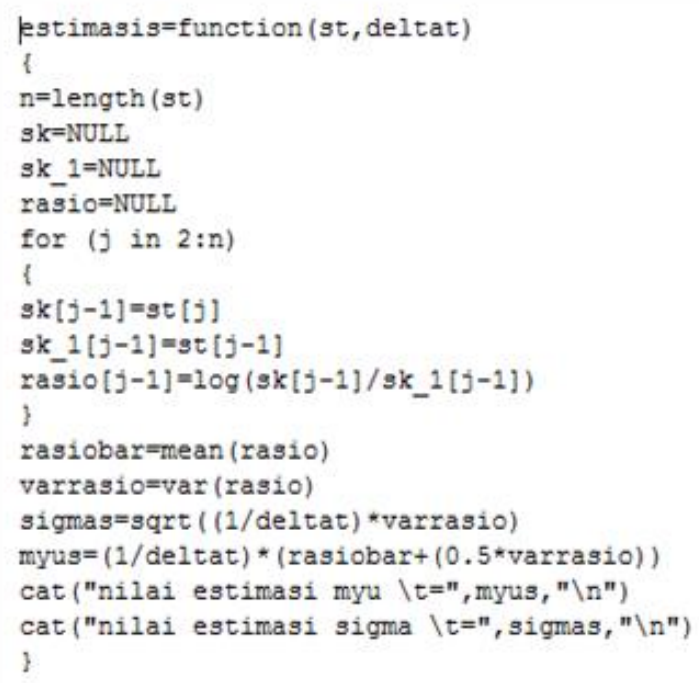

Gambar 2. Syntax R Estimasi Parameter Saham

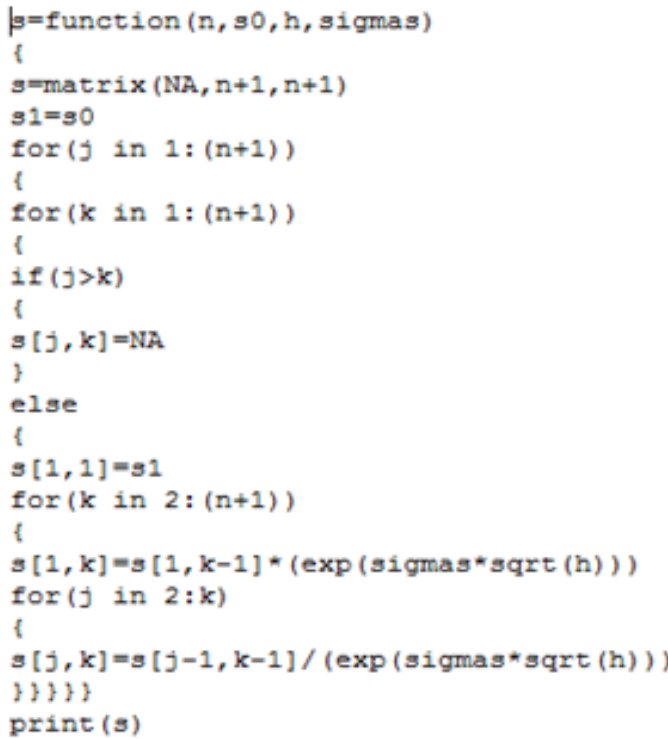

Gambar 3. Syntax R Pohon Binomial Saham

Pada tabel-tabel berikut disajikan besarnya premi tertanggung laki-laki dan perempuan yang masing-masing berusia 20, 30, 40, dan 50 tahun dengan waktu jatuh tempo masing-masing 5, 10, dan 15 tahun. Besarnya manfaat kematian adalah Rp.30.000.000,00, nilai opsi adalah Rp.15.000.000,00 dan ukuran saham yang diinvestasikan adalah 1000 lembar.

Tabel 1. Premi Equity-Linked laki-laki dengan usia dan waktu jatuh tempo tertentu.

\begin{tabular}{cccc}
\hline $\mathbf{x}$ & $\begin{array}{c}\mathbf{T}=\mathbf{5} \\
(\mathbf{R p})\end{array}$ & $\begin{array}{c}\mathbf{T = 1 0} \\
(\mathbf{R p})\end{array}$ & $\begin{array}{c}\mathbf{T = 1 5} \\
(\mathbf{R p})\end{array}$ \\
\hline 20 & 13.951 .094 & 15.360 .902 & 18.072 .395 \\
30 & 13.956 .428 & 15.362 .204 & 18.033 .609 \\
40 & 13.975 .529 & 15.353 .807 & 17.841 .054 \\
50 & 14.067 .236 & 15.362 .058 & 17.487 .166 \\
\hline
\end{tabular}


Tabel 2. Premi Equity-Linked perempuan dengan usia dan waktu jatuh tempo tertentu.

\begin{tabular}{cccc}
\hline $\mathbf{x}$ & $\begin{array}{c}\mathbf{T}=\mathbf{5} \\
(\mathbf{R p})\end{array}$ & $\begin{array}{c}\mathbf{T = 1 0} \\
(\mathbf{R p})\end{array}$ & $\begin{array}{c}\mathbf{T}=\mathbf{1 5} \\
(\mathbf{R p})\end{array}$ \\
\hline 20 & 13.945 .229 & 15.359 .116 & 18.083 .714 \\
30 & 13.951 .443 & 15.360 .560 & 18.053 .268 \\
40 & 13.965 .866 & 15.357 .664 & 17.941 .070 \\
\hline 50 & 14.017 .963 & 15.357 .880 & 17.703 .794 \\
\hline \multicolumn{4}{c}{ Di Indonesia, peluang meninggal }
\end{tabular}

seorang perempuan lebih kecil dibandingkan laki-laki (Tabel TMI III 2011). Pada Tabel 1 dan 2 terlihat bahwa semakin lama waktu jatuh tempo, maka premi yang harus dibayarkan semakin besar. Pada saat $\mathrm{T}=5$, semakin tinggi usia tertanggung, harga premi juga semakin tinggi. Namun sebaliknya, pada $\mathrm{T}=10$,semakin tinggi usia tertanggung maka harga premi semakin rendah.

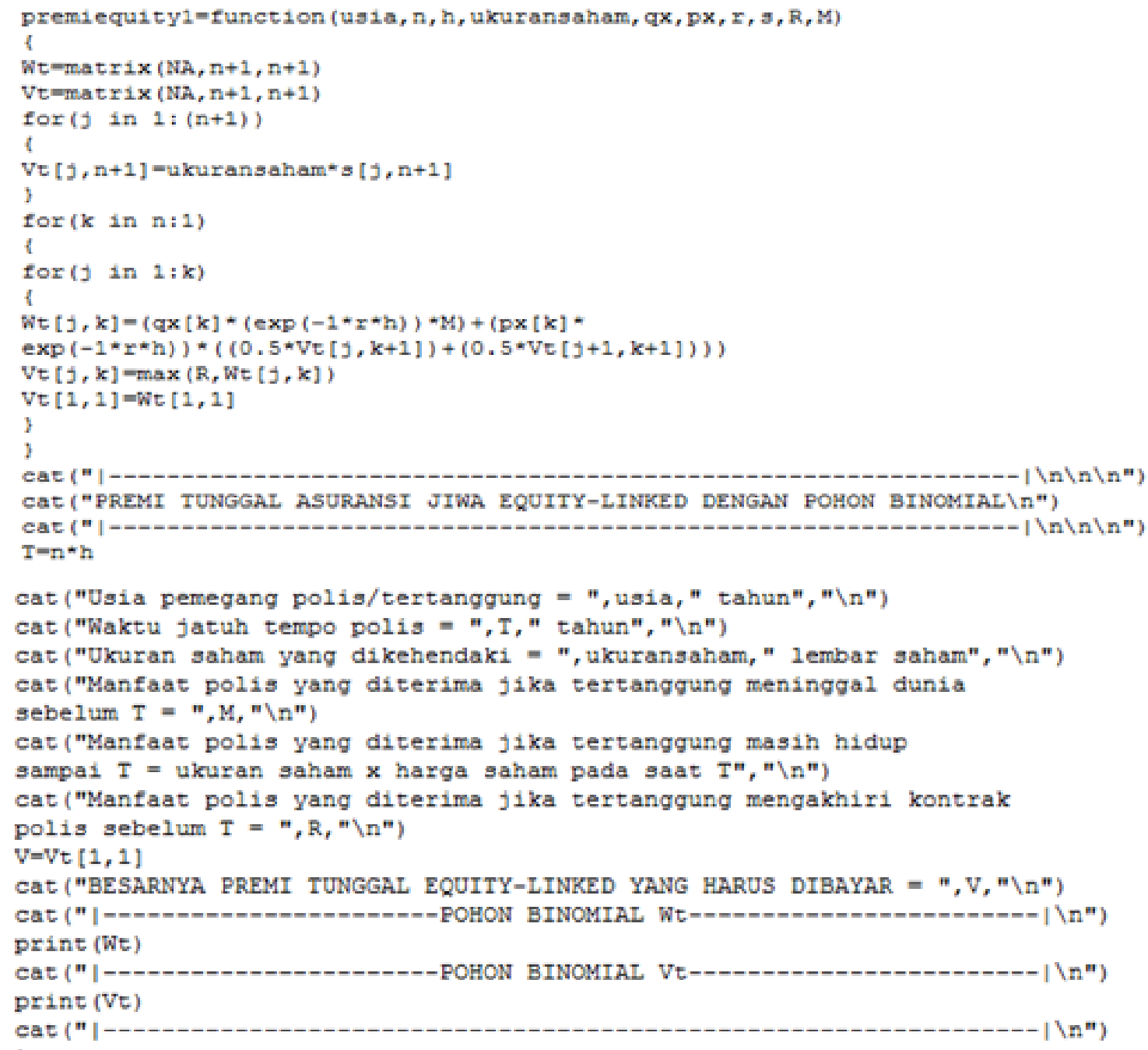

Gambar.4. Syntax R Pohon Binomial Premi Equity-Linked

\section{Kesimpulan}

Berdasarkan

pembahasan

sebelum-nya, dapat diambil kesimpulan

bahwa ketika waktu jatuh tempo kontrak polis pendek, semakin kecil peluang seseorang meninggal dunia, harga premi juga semakin murah. Namun, ketika waktu jatuh tempo kontrak polis panjang, 
semakin kecil peluang seseorang meninggal dunia, harga premi akan semakin mahal. Hal ini bisa dimaklumi karena dengan panjangnya waktu jatuh tempo, peluang harga saham melonjak naik semakin besar, dengan rendahnya peluang meninggal seseorang akan mengakibatkan harga premi juga semakin mahal.

\section{Pustaka}

[1] G. Andreatta and S. Corrodin, Valuing The Surrender Options Embedded in a Portfolio of Italian Guaranteed Participating Policies: a Least Squares Monte Carlo Approach (2003).

[2] W. Shen and H. Xu, The Valuation of Unit-Linked Policies with or Without Surrender Options, The Insurance : Mathematics and economics $\quad(I M E), \quad 37, \quad 79-92$ (2004).

[3] A. R. Bacinello, A Full Monte Carlo Approach to The Valuation of The Surrender Option Embedded in Life Insurance Contacts, The Mathematical and Statistical Methods for Insurance and Finance, 19-26 (2008).

[4] M. Costabile, M. Gaudenzi, I. massabo, and A. Zanette, Evaluating Fair Premiums of Equity-Linked Policies with Surrender Option in A Bivariate Model, Insurance : Mathematics and Economics (IMS), 45, 286-295 (2009).

[5] A. R. Bacinello, Endogeneus Model of Surrender Conditions in Equity-Linked Life Insurance, The Insurance : Mathematics and Economics (IMS), 37 270-296 (2005).

[6] P. Wilmott, Paul Wilmott Introduces Quantitative Finance, John Wiley and Sons : England, 2001 
